\title{
Influencia de la etnia sobre los niveles de $L p$ (a) y sus isoformas
}

\author{
Víctor Casanueva E. '; Carlos Calvo M.2; \\ Ximena Cid C. ${ }^{3}$; Natalia Ulloa N. ${ }^{2}$; Jorge Sepúlveda T. ${ }^{2}$; \\ Cristián Milos G. ${ }^{4}$ M. Teresa Chiang S. $^{5}$
}

\section{Serum lipoprotein (a) in children of pehuenche etnic origin}

Serum levels and frequency distribution of lipoproein \{Lp] [aj in two samples of 71 white and 41 pehuenche children 10 to 15 vears old) cre described These children cre currently dwelling at High Bio-Bio river bosin isololed rural communities of the $v^{\prime}$ llth geopolitical region, midscthern Chile. Lplal mean serum levels for pehuenche and caucasian children were $10.5 \pm 8.2$ and $21.3 \pm 34.5$ respectively $\{p<0.001$ ). Bath samples trequencies were skewed to the left. The prevalence of serum leves cons dered at risk $130 \mathrm{mg} / \mathrm{dll}$ was $21.1 \%$ and $7.3 \%$ for caucasian and pehuenche childen respectively. As for :pial isoforms, an inverse correlation was observed belween isotorm size and is serum level; $r=0.77$ for caucasion and $r=-0.33$ for pehuenche cinidren. Pehuenche chi dren are probably at less polential cordiovascular risk than coucasian children as far as lplal serum levels are concerned.

[Key words: apolipoproleins, lipoproteins, ethnic groups.]

La lipoproteína (a) $[\mathrm{Lp}(\mathrm{a})]$ es una partícula lipoproteica rica en colesterol, similar a la lipoproteína de baja densidad (LDL), que además de apoB-100 contiene una proteína de alto peso molecular denominada apoproteína (a) [apo(a)] 1. La apo(a) es una glicoproteína constituida por múltiples copias de secuencias de 80 a 90 aminoácidos, que se numeran 4 y 5 por su semejanza con los del plasminógeno ${ }^{2}$. Se ha observado que la apo(a) exhibe un polimorfismo de tamaño genéticamente determinado, que se

I. Departamento de Pediatria, Facultad de Medicina, Liniversidad de Concepción.

2. Bioquimico. Departamento de Bioquímica Clínica e Inmunología, Facultad de Farmacia, Universidad de Concepción.

3. Bioquímico. Laboratorio Central, Hospital Clínico Regional Guillermo Grant Benavente. Servicio Salud Concepción, Arauco.

4. Químico Farmacéutico. Departamento de Bioquímica Clínica e Inmunología, Facultad de Farmacia, Universidad de Concepción.

5. Bioquímico. Departamento de Fisiopatologia, Facultad de Ciencias Biológicas, Universidad de Concepción. Proyecto financiado por la Dirección de lnvestigación. Universidad de Concepción, No 948814-1. relaciona en forma inversa con los niveles séricos de $\mathrm{Lp}(\mathrm{a})^{?}$.

Se desconoce la función exacta de la $\mathrm{Lp}$ (a). Por su semejanza estructural con el plasminógeno se postula que tendría acciones aterogénica y trombogénica ${ }^{2}$. Los adultos caucásicos cuyas concentraciones séricas de Lp(a) son mayores que $30 \mathrm{mg} / \mathrm{dl}$ pudiesen tener tres veces más riesgo de afecciones coronarias que los sujetos controles ${ }^{4}$, considerándose a la $\mathrm{Lp}$ (a) un factor independiente para dicho riesgo. Por otra parte, los estudios de Bogalusa en niños blancos y negros han demostrado que la concentración sérica de $L p(a)$ difiere según la variable étnica ${ }^{5}$.

Se han encontrado diferencias significativas en el perfíl lipidico de escolares caucásicos y pehuenches de la cuenca del Alto Bío-Bfo (VIII Región, Chile) $)^{6}$ El objetivo del presente trabajo es describir las concentraciones séricas y la distribución de frecuencia de $L p(a)$ en una muestra de niños de cada una de esas poblaciones y determinar si existe alguna relación entre el tamaño de las respectivas isoformas de apolipoproteína (a) y las concentraciones séricas de Lp(a). 


\section{Material y Método}

En la localidad cordillerana del Alto Bío-Bío (Ra)co y Ralco Lepoy, VIII Región, Chile) se estudiaron dos muestras de niños sanos de 6 a 15 años de edad, una pehuenche y otra caucásica, seleccionados al azar: 41 pehuenches (2l niñas) y 71 caucásicos ( 24 niñas). Para calificar como pehuenche a un nið̃o se exigió que ambos apellidos fuesen de tal origen étnico. Se califıcó como caucásicos a los hijos de padres procedertes de localidades lejanas, que habitasen en la zona en que se realizó el estudio por razones de trabajo y cuyos apellidos fuesen los comunes de la poblaçón chilena no indígena. Los pehuenches viven dispersos en sus comunidades y segregados por idjoma. distancia y accidentes geográficos, lo que obliga a sus nif̂os a asistir a las escuelas en régitnen de internado. Los niños caucásicos, que tienden a vivir en comunidades más compactas, asisten a las mismas escuelas que los primeros y lodos ellos reciben durante el día alimentos proporcionados por la Junta Nacional de Auxilio Escolar y Becas del gobierno chileno. Todos los niños seleccionados fueron examinados por pediatras del Departamento de Pediatría de la Facultad de Medicina de la Universidad de Concepeión. cuyo Comité de Etica aprob6 esta investigación. El examen físico completo inclúa mediciones de peso y talla de acuerdo a estándares descritos anteriormente y búsqueda sistemática de sintomas $y$ signos de enfermednd ${ }^{6}$.

Después de obtener autorización de los caciques locales, padres y los mismos niños, y de un ayuno de 12 horas, se obtuvo de cada niño una muesta de sangre sin anticoagulantes, para mediciones de colesterol total, colesterol lipoproteina de alta densidad (C-HDL). colesterol lipoproteína de baja densidad (C-LDL), triglicéridos (TG), LP(a) e isoformas de apo(a). Los lípidos y lipoproteínas fueron determinados por técnicas enzimáticas previamente descritas ${ }^{6}$. La Lp(a) se midió mediante un inmuno ensayo enzimático no competilivo, usando un anticuerpo monoclonal antiapolipoprotefra (a) como anticuerpo de captura y uno antiapo(b) marcado con peroxidasa como sistema de revelado $^{7}$. Las isoformas de apo(a) se determinaron mediante electroforesis en gel de agarosa, seguida de transferencia a placas de fluoruto de polivinildieno ( $P V D F$ ), usando como sistema de revelado un anticuerpo antiapolipoproteína (a) marcado con peroxidasa y quimioluminiscencia sobre placas de fotografia. ${ }^{8}$. Puesto que la distribución de Lp(a) no es gausiana, se utilizó la prueba no paramétrica de Mann y Witney para comparar los promedios de ambos grupos. La correlación entre el tamallo de isoforma de apo(a) y la concentración de $L_{p}$ (a) se calculó usando la correlación de Spearman.

\section{Resultados}

La distribución de frecuencia de las concentraciones séricas de $\mathbf{L p}(\mathbf{a})$ en niños pehuenches y caucásicos se expresa en las figuras 1a y 1 b. Las concentraciones de $L p(a)$ en los niños pehuenches dieron resultados desviados hacia la izquierda, es decir, hacia las concentraciones menores, encontrándose cifras mayores de $\mathbf{3 0}$ $\mathrm{mg} / \mathrm{dl}$ en solamente tres de estos niños. En los caucásicos, en cambio, en IS niños ellas eran superiores a $30 \mathrm{mg} / \mathrm{dl}$, consideradas como límite superior de lo "jnocuo"4. Las concentraciones de $L_{P}$ (a) fueron, respectivamente en pehuenches y caucásicos (promedio y desviación estándar), $10,5 \pm 6,2$ y $21,3 \pm 34,5 \mathrm{mg} / \mathrm{dl}(\rho<0,001)$.

Las isoformas de apo(a) se determinaron solamente en una submuestra de niños pehuenches y colonos (n: 50). Con el método empleado se detectaron hasta 19 isoformas de apo(a) cuyo tamaño fluctuaba entre 540 y 960 kilodalton (kd). En los casos de individuos heterocigotos que presentaban dos bandas de los fenotipos, sólo se consideró la más pequeña, pues en la mayoría de ellos eran éstas las cuantitativamente predominantes. La distribución de tamaño de isoforma de apo(a) fue diferente en los niños pehuenches y caucásicos, lo que se hizo evidente al establecer correlaciones cntre el tamaño de las isoformas de apo(a) y las concentraciones séricas de $\mathrm{Lp}$ (a). En los niños caucásicos se registró una correlación inversa entre el tamaño de la isoforma y la concentración plasmática de $\mathbf{L p}(a)(r=-0,77)$, la que no fue tan evidente para la población pehuenche $(r=$ $-0,33$ ) (figuras $2 c$ y $2 d$ ).

\section{Comentario}

Las concentraciones séricas de $\mathrm{L}_{\mathrm{P}}$ (a) aquí descritas provienen de niños de diferentes etnias que viven en una misma comunidad rural aislada $y$ tienen estilos de vida similares. La población pehuenche del Alto Bío-Bío es una de las menos miscegenadas de Chile, con aporte genético no indígena inferior a $2 \%{ }^{10}$. En Bogalusa los niños fueron clasificados como "blancos y negros", aunque entre las personas estadounidenses de raza negra la proporcion de genes caucásicos puede ser del orden de $25 \%$. En nuestra muestra "caucásica" la concentración promedio de $L p(a)$ sérica fue similar a la de los niños "blancos" de Bogalusa y significativamente superior que en los niños pehuenches. La distribución de concentración de $L_{p}(a)$ en los niños caucásicos del Alto Bío-Bío se asemeja a la descrita en otras poblaciones de semejante origen étnico en diferentes lugares del mundo. 11 . Los dos grupos étnicos de esta muestra presentaron la misma distribución sesgada hacia 

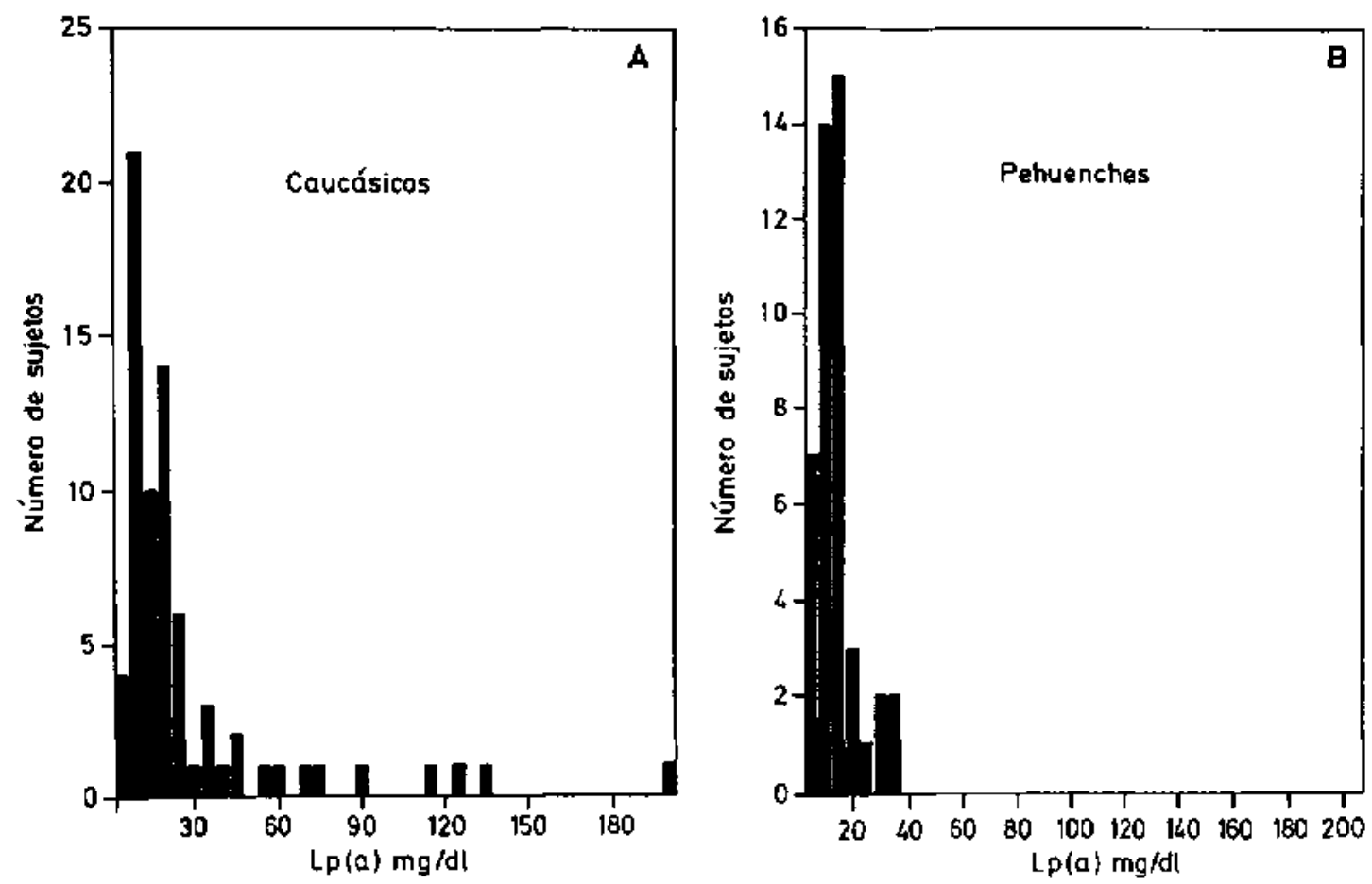

Figora 1. Distribución de la concentración de lipoproteina (a) en el suero de niños caucásicos (A) y pehuenches (B).
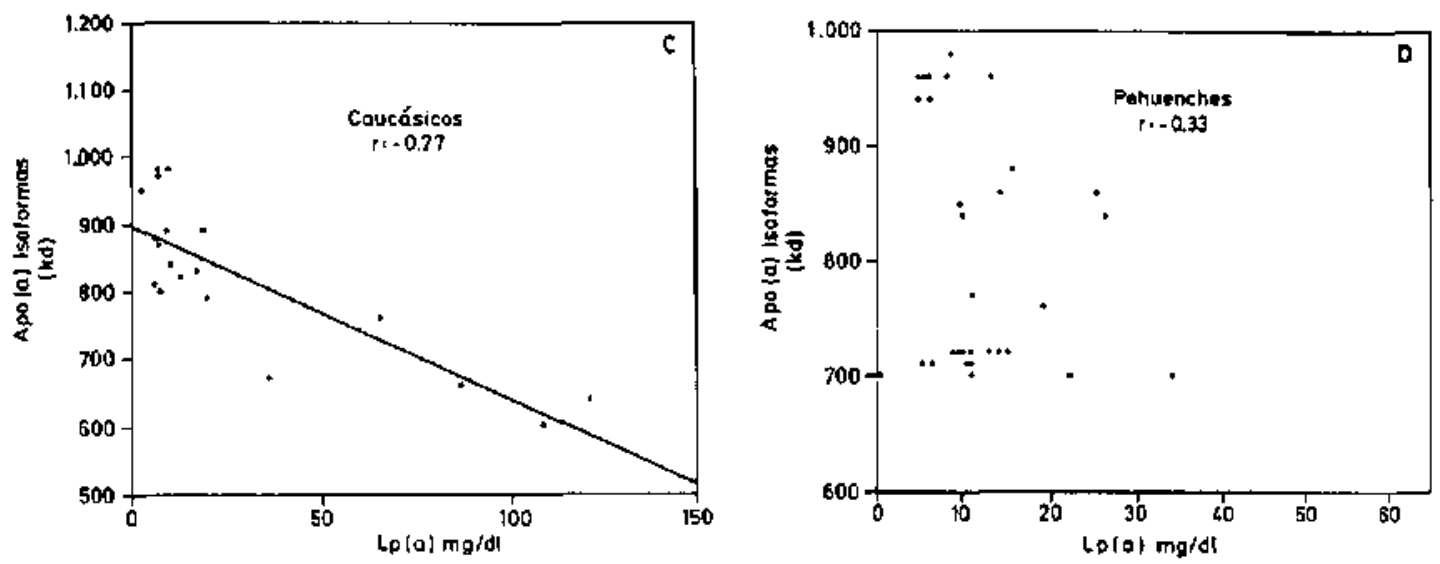

Figura 2. Relación entre el tamaño de las isoformas de apolipoproteína (a) y la concentración sérica de lipoproteína (a) en el suero de niños caucísicos (C) y pehuenches (D).

la izquierda, a diferencia de los niños de raza negra de Bogalusa, cuya curva de dispersión era cercana a la "normal", siendo esa raza la única que presenta esa forma de dispersión de las concentraciones séricas de $\mathrm{Lp}(\mathrm{a})^{5}$.

El estudio de Bogalusa no detectó correlación entre las concentraciones séricas de Lp(a), edad, sexo, obesidad y tabaquismo en niños blancos o negros 5 . Tampoco se ha encontrado correlación de aquellas con las de colesterol total, C-HDL, C-LDL ${ }^{12}$ y triglicéridos. En esta muestra tampoco encontramos correlaciones entre la concentración de Lp(a), edad, peso, estatura, colesterol total, sus fracciones y triglicéridos 
en el suero de niños pehuenches y caucásicos. Puesto que en los estudios de Bogalusa no se determinaron las isoformas de apo(a), no encontramos patrones de referencia para niños y adolescentes.

Las concentraciones de $\mathrm{Lp}(\mathrm{a})$ en el suero tienden a ser similares en los miembros de una misma familia y las isoformas de apo(a) se heredan $^{12}$. Se ha señalado que en los hijos de padres con antecedentes de infarto precoz del miocardio la concentracion promedio de $L p(a)$ es de $27 \mathrm{mg} / \mathrm{dl}$, casi el doble que en los controles (14 $\mathrm{mg} / \mathrm{dl})$ lo que reafirma la influencia genética ${ }^{13}$. La región de la secuencia 4 de la apo(a), homologa a la del plasminógeno, está presente en múltiples copias, cuyo número varía y es determinado genéticamente, originando diversas isoformas de apo(a) y por consiguiente diferentes concentraciones de $\mathrm{Lp}(\mathrm{a})^{1}$. Las concentraciones séricas de $L p(a)$ varían considerablemente en cada individuo, siendo inversamente correlacionadas con el tamaño de la apo(a) y el número de regiones codificantes de la secuencia 4 presentes en el gen de la apo(a) ${ }^{14}$. La escasa correlación entre el tamaño de las isoformas de apo(a) y la concentración de $\mathrm{Lp}$ (a) observada entre los niños pehuenches podría explicarse por condiciones de vida cerradas que de una u otra forma los emparentan, favoreciendo mayor uniformidad entre sus isoformas. Entre los niños pehuenches, isoformas de apo(a) de igual masa molecular se asociaron a leves diferencias de las concentraciones de Lp(a), dentro del reducido margen de variación de estas últimas.

Se han encontrado diferencias significativas en la frecuencia de los alelos de la apo(a) entre caucásicos y africanos que viven en EEUU ${ }^{9}$, lo que permitiría especular que las diferencias encontradas en las isoformas de niños pehuenches y caucásicos pudiesen tener base genética.

\section{Resumen}

Se midieron las concentraciones séricas y la distribución de frecuencia de lipoproteína (a) en 71 niños caucásicos y 41 pehuenches (de 6 a 15 años de edad) que habitan en la zona del Alto Bío-Bío, VIII Región geopolítica de Chile. Adicionalmente se registraron las isoformas de apolipoproteína (a) en 50 de los participantes. Las concentraciones de lipoproteína(a) fueron 10,5 \pm
6,2 y $21,3 \pm 34,5 \mathrm{mg} / \mathrm{dl}$, respectivamente, en los niños pehuenches y caucásicos ( $p<0,001)$. La distribución de las frecuencias de ambos grupos mostró inclinación hacia las concentraciones más bajas de una curva "normal". La prevalencia de concentraciones séricas de lipoproteina (a) consideradas riesgosas en términos de enfermedades cardiovasculares (> $30 \mathrm{mg} / \mathrm{dl}$ ) fue de $21.1 \%$ y $7,3 \%$, respectivamente, para niños caucásicos y pehuenches. En Ios caucásicos se observó una correlación inversa entre el tamaño de la isoforma de apolipoproteína (a) y la concentración plasmática de lipoproteína (a) $(r=-0,77)$, lo que fue menos claro en la población pehuenche $(\mathrm{r}=-0,33)$.

(Palabras clave: apolipoproteínas, lipoproteínas, grupos étnicos, pehuenche, caucásico.)

\section{Referencias}

1. Uterman G: The mistery of $\mathrm{Lp}_{\mathrm{p}}$ (a) Science $1989 ; 246$ 904-910.

2. Scanu A, Fless A: Lipoprotein (a). Heterogenicity and biological relevance. J Clin Inv 1990; 85: 1709-1715.

3. Bruckers $E, N g u y e n ~ M: ~ L p(a)$ un nouvcau facteur de risque cardiovasculaite. Cah Nutr Dietet 1993; 28: $151-156$.

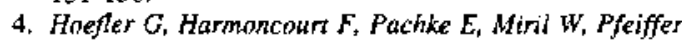
$K$, Kostner $G$; Lipoprotein (a). A risk factor for myocardial infarction. Artherosclerosis 1988; 8: 398-401.

5. Srinivasan S. Dahlen $G_{+}$Jarpa $R$. Webber L, Berenson $G$ : Racial (black-white) differences in serum $L p(a)$ distribution and its relation to parental myocardial infarction in children. Bogalusa Heart Siudy. Circulation $1991 ; 84: 16-167$.

6. Casuntreva V. Milos C. Loperegui B. Chiang M. Cid $X$ : Influencia de la etnia y el ambiente en el perfil lipídico de escolares de la VIII Región. Rev Med Chi] 1994: 122: 496-503.

7. Hevia L, Chapman J, Thillet H: Does apo(a) beterogenicity influence lipoprotein (a) effects on fibrinolysis? Blood 1993; 82: 392-39?.

8. Doucet C, Huby $T$, Chapman J, Thillet $J$ L Lipoprotein (a) in the chimpanzee: relationship of apo(a) phenotype to elevated plasma LP(a) levels. J Lipid Res $1994 ; 35: 263-270$.

9. Marcovina $S$. Albers $J$, Jacobs $D$, et al: $L p(a)$ concentrations and apo(a) phenotypes in caucasian and african americans. The CARDIA study. Atheroesclerosis 1993; 13: 1037-J045.

10. Llop E. Harb Z, Acuña M. Barton S. Aspillaga E, Rithhammer F: Composición genética de la poblacion chilena: los pehuenches de Trapa-Trapa. Rev Med Chil 1993; 121: 494-498.

11. Sandholzer C. Sana $N$, Karkk $J$, et al: Apora) isoforms predict risk for coronary beart diseases. A srudy in six populations. Athetoesclerosis $1992 ; 12: 1214$ 1226. 
12. Utermann $G$, Menzel $H$. Krafi $H$ : Lp(a) glycopro. tein phenotypes. Inheritance and telation $10 \mathrm{Lp}(\mathrm{a})$ concentrations in plasma. J Clin lnv 1987: 80: 458465.

13. Mórquez A, Mendoza S, Carrasco H, Hamer T, Glueck $C$ : High $\mathbf{L}(a)$ in children from kindred with parental premature myocardial infarction. Pediatr Res 1993; 3445: 670-674.

14. Lackner $C$. Buerwinkler $E$, Lefferl $C$, Rehmiy $T$. Hobbs $H$ : Molecular basis of a apo(a) isoform size heterogenicity as revealed by pulsed field gel electro. phoresis. J Clin lnvest 1991; 87: 53-6].

Esta publicación está disponible en copias de microfilms de 16 y 35 mm y microfichas de $105 \mathrm{~mm}$, las que pueden solicitarse a:

University Microfilms International

300 North Zeeb Road

Ann Arbor, Michigan 48106, USA.

This journal is also available in $16 \mathrm{~mm}$ microfilm. $35 \mathrm{~mm}$ microfilm and 105 mm microfilm copies through

University Microfilms International, 300 North Zeeb Road,

Ann Arbor, Michigan 48106, USA. 